\title{
Closed Loop Control of Zero Voltage Switching DC-DC Converter to Generate Three Outputs
}

\author{
Prasad JS ${ }^{1 *}$, Obulesh YP ${ }^{2}$ and Babu CS $^{3}$
}

${ }^{1}$ LBR College of Engineering, Mylavaram, Andhra Pradesh, India

${ }^{2}$ KL University, Vijayawada, Andhra Pradesh, India

${ }^{3} J N$ Tech. University, Kakinada, Andhra Pradesh, India

\begin{abstract}
Hard switching specifies the stressful switching behavior of the controlled switches. During the turn-off and turn-on processes, the power electronic device has to withstand high current and voltage simultaneously, resulting in high stress and switching losses. The switching loss is directly proportional to the switch frequency, thus reducing the maximum switch frequency of the power electronic converter. The concept was to incorporate resonant tanks in the converters to create oscillatory (usually sinusoidal) voltage and/or current waveforms, so the zero current switching (ZCS) or zero voltage switching (ZVS) conditions can be achieved for the power control switches. The Soft-switched power converters are generally utilizing the resonance condition. Resonance condition is generally occurred just during the turn-off and turn-on processes, so as to create ZCS and ZVS across each switch. The Regulated three and five multiple-output dc-dc converter under zero-voltage switching (ZVS) condition is proposed. The converter is consists of three outputs altogether. With the help of two asymmetric half bridge converters, the first and second outputs are controlled. Based on the phase shift between two asymmetric half bridge converters, the third output is controlled. At high switching frequency, these multiple-output dc-dc converters can give higher efficiency. The various stages of operation, soft switching condition and controlling schemes are also explained. A closed loop and open loop control techniques of the three multiple output converter is explained.
\end{abstract}

Keywords: DC-DC converter; Zero Voltage Switching (ZVS); Zero Current Switching (ZCS); Switching losses; Full bridge; Inverter; Duty cycle; Switching period; Pulse Width Modulation (PWM)

\section{Introduction}

A DC-DC converter is an electronic circuit which converts a source of direct current (DC) from one voltage level to another. It is a class of power converter. The DC-DC converters are widely used for battery power supply in different electronic devices like mobile phones, MP3 players and laptops. There is a scope for developing DCDC converters to generate multiple dc output voltage from single dc power supply. These multiple output voltages are feed to the different $\mathrm{dc}$ load applications. This scheme of developing multiple dc voltage levels from a single dc supply source can reduce the overall device area. The $\mathrm{dc}$ voltage provided by rectifier or battery contains more ripples and it is not a constant value and it is not suitable for many electronic devices. To overcome this problem, the $\mathrm{dc}$ - $\mathrm{dc}$ voltage regulators are used to control the ripples even when change in the input voltage or load current.

The switching mode type dc-dc converters power supply is widely used because it uses a switch in the form of transistor type and less loss components such as transformers, inductors and capacitors for controlling the output voltage. The switched mode power supply contains two different parts: control part and power part. The majority of the work is carried out by the control part for getting better control of output voltage. Generally the MOSFET is used as a control switch in Switched mode power supply for stabilizing the required output voltage. The MOSFET switches are not to be conducted continuously and they operate only under specific frequency interval, hence these switches are useful for a long future and also provide less power loss the converter circuit. The basic structure of Switched mode power supply is used for stepping up or stepping down of input DC voltage. The SMPS circuit is basically consisting of a filter at the output side for removing the ripples due to switching [1].
The main objective of the project is to regulate three multiple output voltages with dc-dc zero-voltage switching (ZVS) converter. The converter is consisting of three multiple outputs voltages. With the help of two asymmetric half bridge converters, the first and second outputs are controlled. Based on the phase shift between two asymmetric half bridge converters, the third output is controlled. ZVS is realized for all the main switches. At high switching frequency, these multipleoutput dc-dc converters can give higher efficiency. The various stages of operation, soft switching condition and controlling schemes are also proposed. A closed loop and open loop control techniques of the three multiple output converter is explained.

Closed-loop System Transfer Function. The Transfer Function of any electrical or electronic control system is the mathematical relationship between the systems input and its output, and hence describes the behavior of the system.

\section{Proposed Three Multiple Output Zvs Dc-Dc Converter}

The Figure 1 shows the main diagram of three multiple outputs converter consists of the two asymmetrical half bridge

ZVS DC-DC converter. Figure 2 shows the control signal of the converter sand it is connected to the three single phase

*Corresponding author: Prasad JS, LBR College of Engineering, Mylavaram, Andhra Pradesh, India, Tel: 08659 - 222933; E-mail: janapatisivavaraprasad@gmail.com

Received July 02, 2015; Accepted August 22, 2015; Published September 15, 2015

Citation: Prasad JS, Obulesh YP, Babu CS (2015) Closed Loop Control of Zero Voltage Switching DC-DC Converter to Generate Three Outputs. J Electr Electron Syst 4: 156. doi:10.4172/2332-0796.1000156

Copyright: (c) 2015 Prasad JS, et al. This is an open-access article distributed under the terms of the Creative Commons Attribution License, which permits unrestricted use, distribution, and reproduction in any medium, provided the original author and source are credited. 
Citation: Prasad JS, Obulesh YP, Babu CS (2015) Closed Loop Control of Zero Voltage Switching DC-DC Converter to Generate Three Outputs. J Electr Electron Syst 4: 156. doi:10.4172/2332-0796.1000156

Page 2 of 12

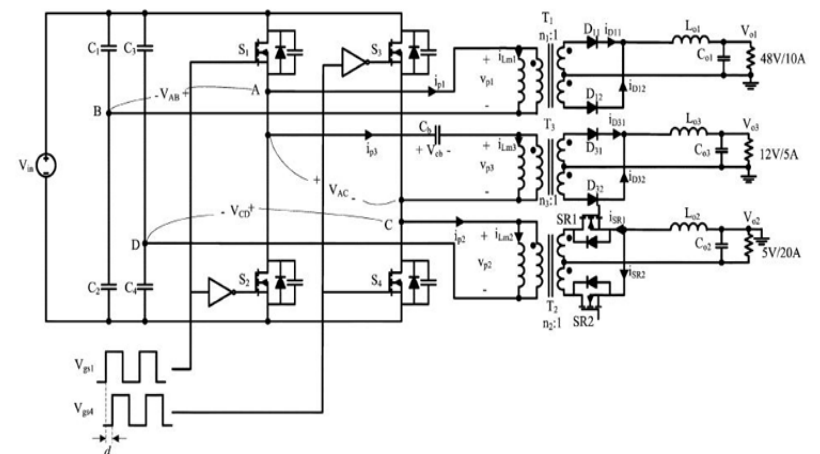

Figure 1: Three Multiple output ZVS dc-dc converter.

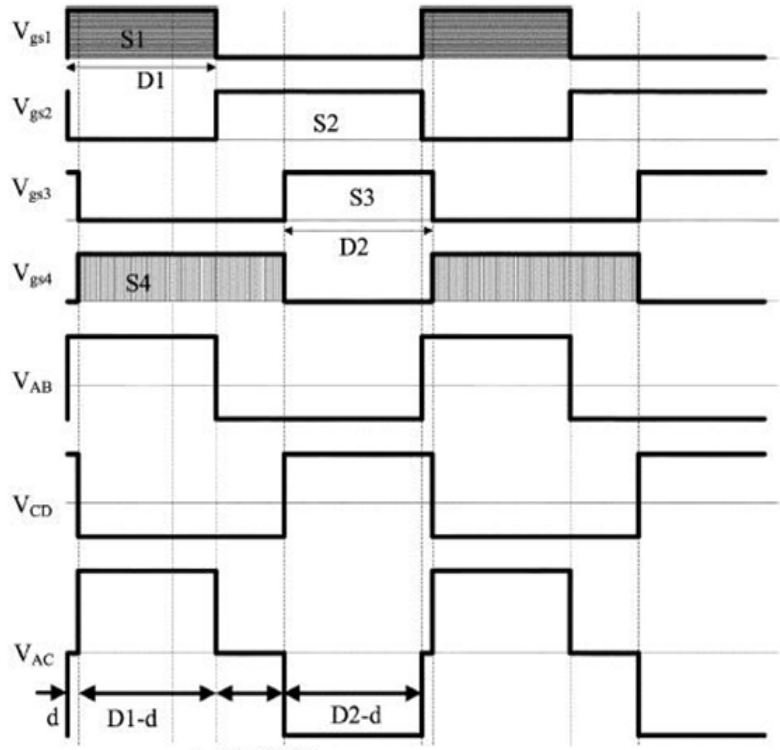

$1-\mathrm{D} 1-\mathrm{D} 2+\mathrm{d}$

Figure 2: Control signals of the three multiple-output dc-dc converter.

Multiple output converter. Multiple outputs ZVSDC-DC transformers [2].

\section{Characteristic of the three multiple output converters}

The multiple-output ZVS dc-dc converter is shown in Figure 1 Since the second output ${ }_{02}$ is low voltage and high current output, we use self-driven synchronous rectification to reduce rectification loss and improve efficiency. All three outputs are regulated through the switches in the primary side. The control signals are shown in Figure 3, where and are the voltage across transformer T1 and T2, respectively, while is the voltage applied to blocking capacitor and transformer T3.

The first output is regulated through the duty cycle of the first asymmetrical half bridge converter which is composed of switches $\mathrm{S} 1-\mathrm{S} 2$ and capacitors $\mathrm{C} 1-\mathrm{C} 2$. Based on the phase shift between two asymmetric half bridge converters, the third output is controlled which is composed of switches S3-S4 and capacitors C3-C4 (Figures 4-9). Based on the phase shift between two asymmetric half bridge converters, the third output is controlled. Since ZVS can be realized for all the main switches, this converter operates at high efficiency under high switching frequency [3].

According to the volt-second balance of the output inductors, we can derive the output voltages of the converter. The first output voltage 01 is

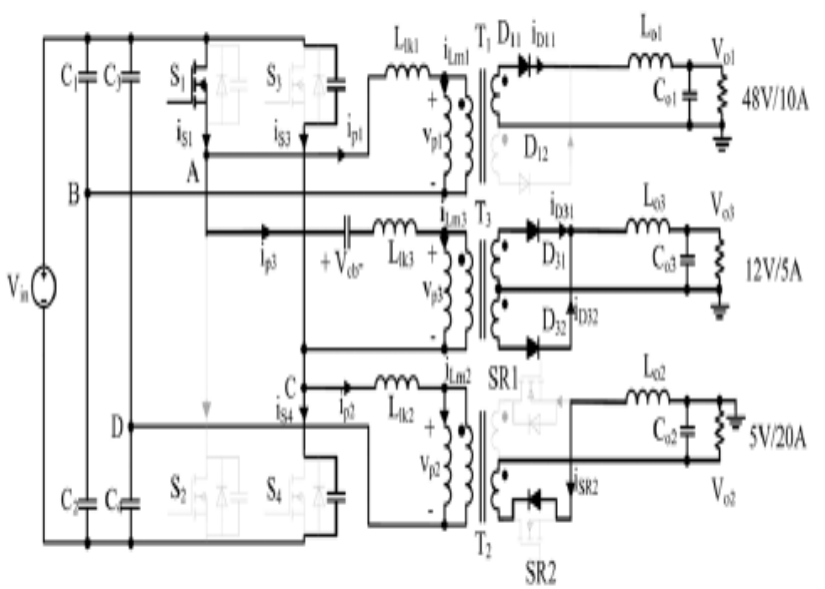

Figure 3: Mode 1 of the proposed multiple-output dc-dc converters.

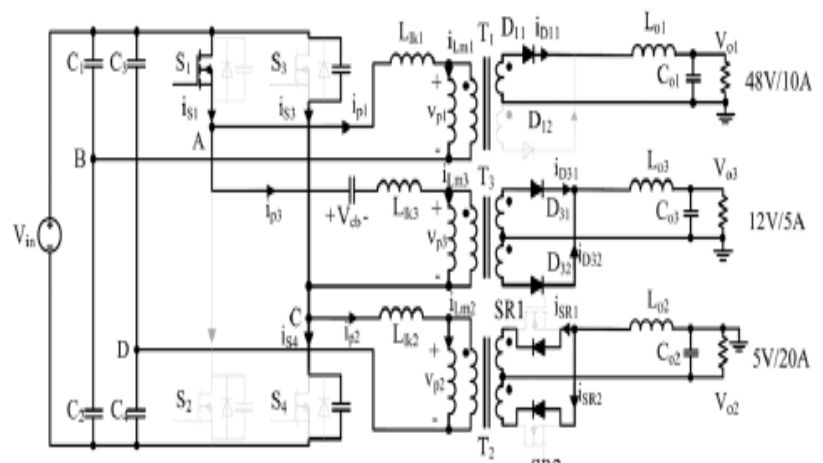

SR2

Figure 4: Mode 2 of the proposed multiple-output dc-dc converters.

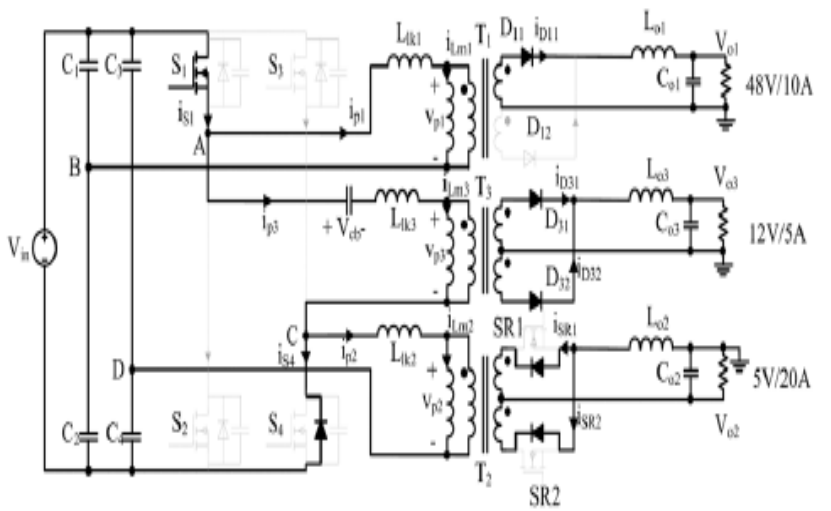

Figure 5: Mode 3 of the proposed multiple-output dc-dc converters. 
Citation: Prasad JS, Obulesh YP, Babu CS (2015) Closed Loop Control of Zero Voltage Switching DC-DC Converter to Generate Three Outputs. J Electr Electron Syst 4: 156. doi:10.4172/2332-0796.1000156

Page 3 of 12

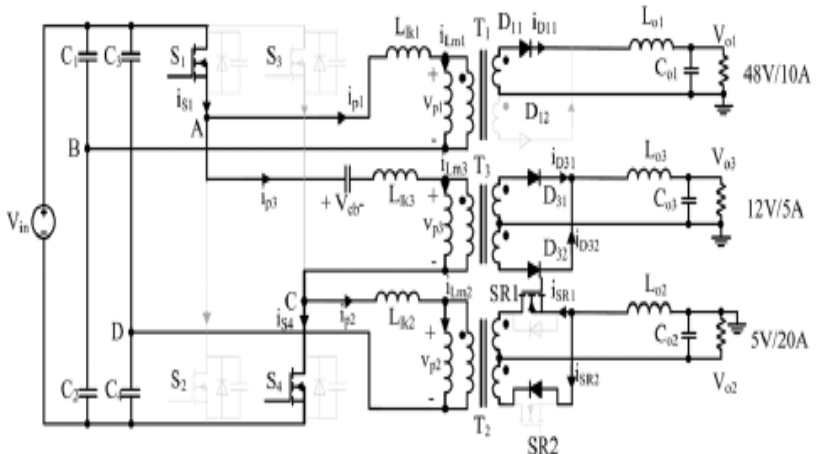

Figure 6: Mode 4 of the proposed multiple-output dc-dc converters.



Figure 7: Mode 5 of the proposed multiple-output dc-dc converters.

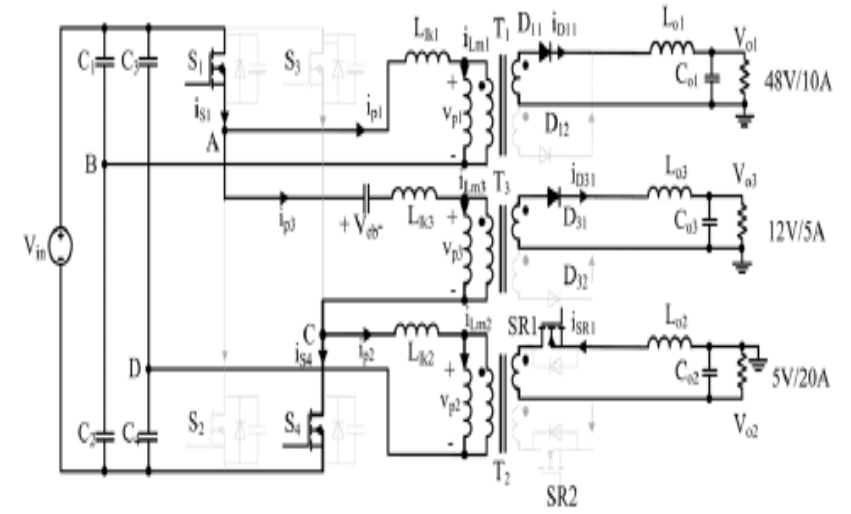

Figure 8: Mode 6 of the proposed multiple-output dc-dc converters.

$$
V_{01}=2 \cdot V_{i n} \cdot D_{1}\left(1-D_{1}\right) \cdot \frac{1}{n_{1}}
$$

the first asymmetrical half bridge converter, equation 1 is the turn ratio of transformer $\mathrm{T} 1$. The second output voltage 02 is

$$
V_{02}=2 \cdot V_{\text {in }} \cdot D_{1}\left(1-D_{1}\right) \cdot \frac{1}{n_{1}}
$$

Where is the input dc voltage, equation 2 is the duty cycle of the second asymmetrical half bridge converter, equation 2 is the turn ratio of transformer $\mathrm{T} 2$.

The expression of the third output voltage 03 is different and depends on both duty cycles 1 and 2 . When duty cycle 1 is larger than duty cycle 2 , the third output voltage 03 is

$$
V_{03}=V_{i n} \cdot\left(D_{1}+D_{2}-2 \cdot d\right) \cdot \frac{1}{n_{3}}+V_{i n} \cdot\left(D_{1}-D_{2}\right) \cdot(1-2 \cdot D 1+2 \cdot d 1 n 3)
$$

When duty cycle 1 is smaller than duty cycle 2 , the third output voltage 03 is

$$
V_{03}=V_{\text {in }} .\left(D_{1}+D_{2}-2 \cdot d\right) \cdot \frac{1}{n_{3}}+V_{\text {in }} .\left(D_{1}-D_{2}\right) \cdot(1-2 \cdot D 2+2 \cdot d 1 n 3)
$$

Where is the input dc voltage, ${ }_{1}$ and ${ }_{2}$ are the duty cycles of the first and second asymmetrical half bridge converters respectively, is the phase shift of the switch S4 to the switch S1, and 3 is the turn ratio of transformer T3.

For simplifying the expression of the third output voltage 03 , we compare the two equations. Therefore, the third output voltage 03 can be simplified as

$$
V_{03}=V_{i n} \cdot\left(D_{1}+D_{2}-2 \cdot d\right) \cdot \frac{1}{n_{3}}
$$

\section{Operation stages of the proposed three multiple output Dc- Dc converter}

Before the analysis, we first make the following assumptions.

1. The duty cycles 1 and 2 are both near 0.5 and almost same, so the voltage across capacitor, which is $(1-2)$. (When duty cycle 1 is larger than duty cycle 2 ) or $(2-1)$. (When duty cycle 1 is smaller than duty cycle 2 ), and is very small compared to the input voltage, and therefore can be ignored.

2. The ZVS of the switches S1-S2 is realized through the energy stored in the output inductor of the third output and the ZVS of the switches S3-S4 is realized through the energy stored in the leakage inductor of transformer T2 and T3.

3. The capacitors $\mathrm{C} 1-\mathrm{C} 4$ and are so large that the voltages across them are considered to be constant.

4. The output inductors are so large that they are considered as current sources.

Stage $1(\mathrm{t} 0-\mathrm{t} 1)$ : Before the starting of this stage, the controlled switches S1 and S3 are on, and the first and second outputs are transferring energy to the load while the third output is freewheeling. At time t0, the switch S3 is turned off. The sum of primary current 1 and 2 begins to charge the parasitic capacitance of the switch S3, and discharge the parasitic capacitance of the switch S4. The voltage turns positive, so the current through the diode D31 begins to increase from zero. The diodes D31 and D32 conduct simultaneously and the voltage across the transformer T3 3 is clamped to zero [4].

Stage 2(t1-t2): At the time of $\mathrm{t} 1$, the parasitic capacitance voltage of switch S4 is discharged to 2. Since the voltage across the capacitor $\mathrm{C} 4$ is 2 , the voltage is zero. Therefore, the current through the synchronous rectifier SR 2 begins to decrease and the current through the synchronous rectifier SR1 begin to increase from zero. Since the synchronous rectifiers SR1 and SR2 conduct simultaneously, the voltage across the transformer T2 2 is clamped to zero.

Stage $3(\mathrm{t} 2-\mathrm{t} 3)$ : At the time of $\mathrm{t} 2$, the parasitic capacitance voltage of switch S4 is discharged to zero. Then the sum of current 2 and 3 begins to flow through the body diode of the switch S4, creating ZVS 
Citation: Prasad JS, Obulesh YP, Babu CS (2015) Closed Loop Control of Zero Voltage Switching DC-DC Converter to Generate Three Outputs. J Electr Electron Syst 4: 156. doi:10.4172/2332-0796.1000156

Page 4 of 12

condition for the switch S4.

Stage $4(\mathrm{t} 3-\mathrm{t} 4)$ : At time $\mathrm{t} 3$, the gate signal of the switch $\mathrm{S} 4$ is applied, and the switch S4 is ZVS turned on. Then the sum of current ${ }_{2}$ and ${ }_{3}$ begins to flow through the switch $\mathrm{S} 4$.

Stage $5(\mathrm{t} 4-\mathrm{t} 5)$ :At time $\mathrm{t} 4$, the current through the synchronous rectifier SR2 decreases to zero and the current through the synchronous rectifier SR1 increases to the second output current [5].

Stage 6 ( $\mathrm{t} 5-\mathrm{t} 6)$ : At time $\mathrm{t} 5$, the current flowing through the secondary side diode D32 starts decreasing to zero and the current through the diode D31 increases to the third output current [6].

Stage 7 ( $t 6-t 7)$ : At time t6, the switch $S 1$ is turned off, and the sum of primary current 1 and 3 begins to charge the parasitic capacitance of the switch S1 and discharge the parasitic capacitance of the switch S2 (Figures 9-13).

Stage $8(\mathrm{t} 7-\mathrm{t} 8)$ : At the time of $\mathrm{t} 7$, the parasitic capacitance voltage of switch S2 is discharged to 1. Since the voltage across the capacitor $\mathrm{C} 2$ is 2, the voltage is zero. The current through the diode D11 begins to decrease and the current through the diode D12 begins to increase from zero. As the diode D11 and D12 conduct simultaneously, the voltage across the transformer T1 1 is clamped to zero [7].

Stage 9 (t8-t9): At the time of $\mathrm{t} 8$, the parasitic capacitance voltage of the switch S2 is discharged to zero. Then the sum of primary ${ }_{1}$ current ${ }_{3}$ and begins to flow through the body diode of the switch S2, creating ZVS condition for the switches S2.

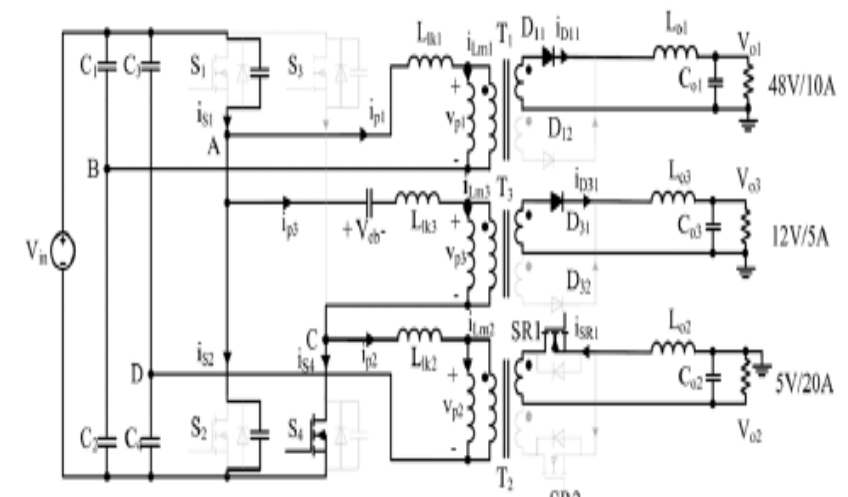

SR2

Figure 9: Mode 7 of the proposed multiple-output dc-dc converters.

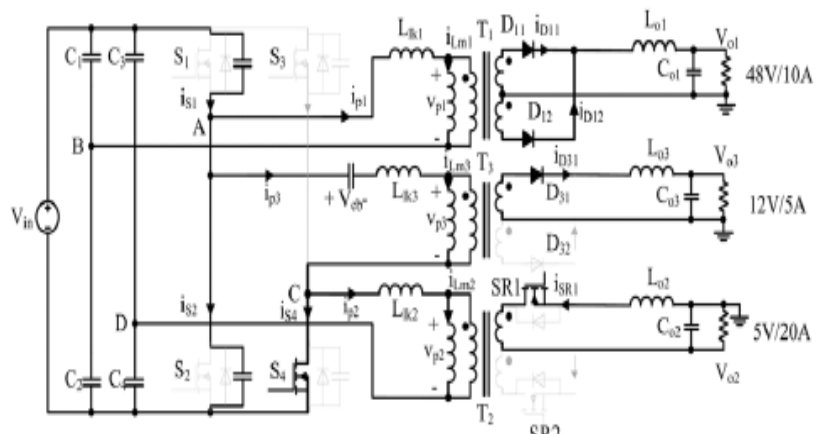

Figure 10: Mode 8 of the proposed multiple-output dc-dc converters.

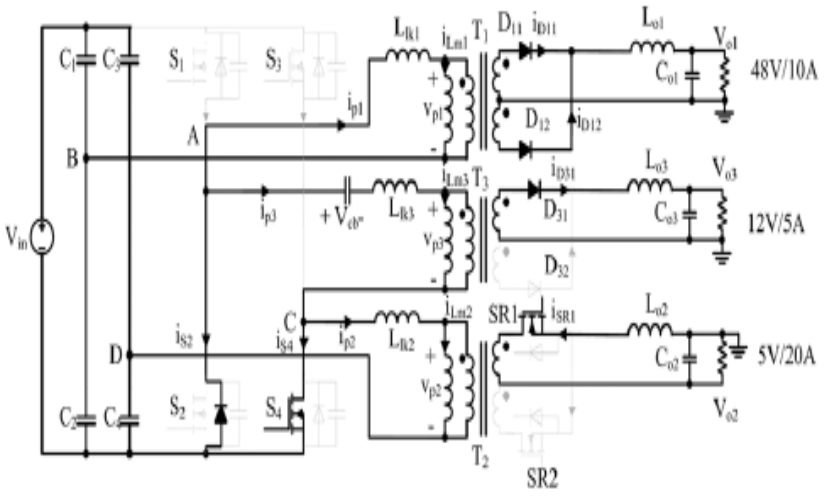

Figure 11: Mode 9 of the proposed multiple-output dc-dc converters.

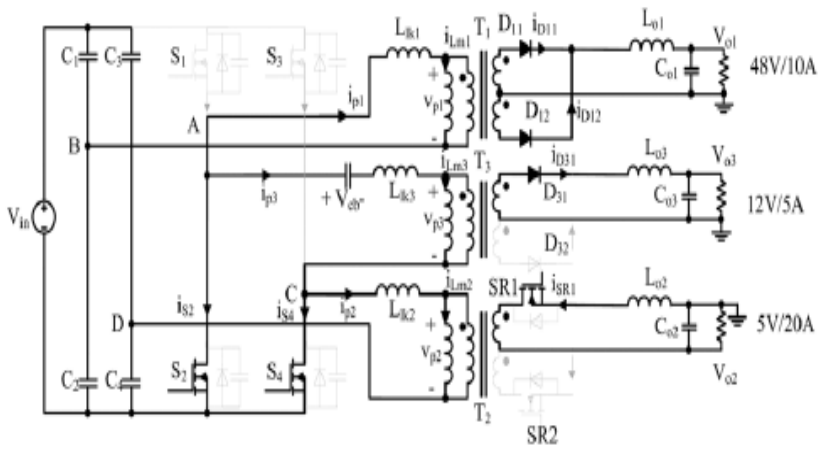

Figure 12: Mode 10 of the proposed multiple-output dc-dc converters.

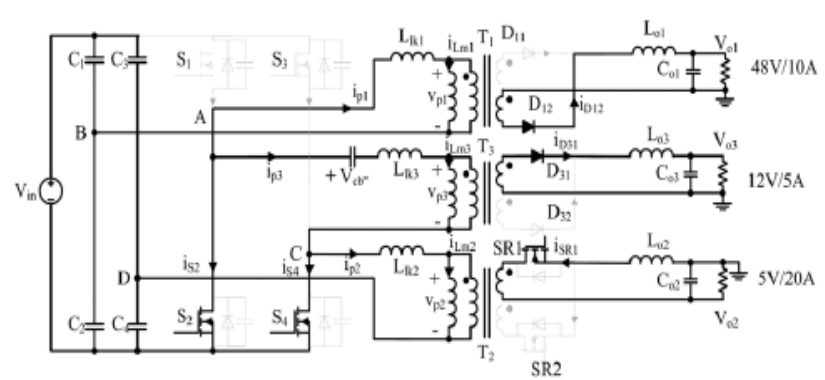

Figure 13: Mode 11 of the proposed multiple-output dc-dc converters.

Stage 10 (t9-t10): At time $\mathrm{t} 9$, the gate signal of the switch S2 is applied, and the switch S2 is ZVS turned on. The sum of primary current 1 and 3 begins to flow through the switch S2.

Stage $11(\mathrm{t} 10-\mathrm{t} 11)$ : At time $\mathrm{t} 10$, the current through the diode D11 decreases to zero and the current through the diode D12 increases to the first output current.

\section{Simulink Model of the Three Multiple Outputs Dc-Dc Converter}

Simulink model of the three outputs converter is shown in the Figure 14. In this model we have taken $400 \mathrm{~V}$ input to the full bridge inverter. The full bridge inverter which is converted direct current 


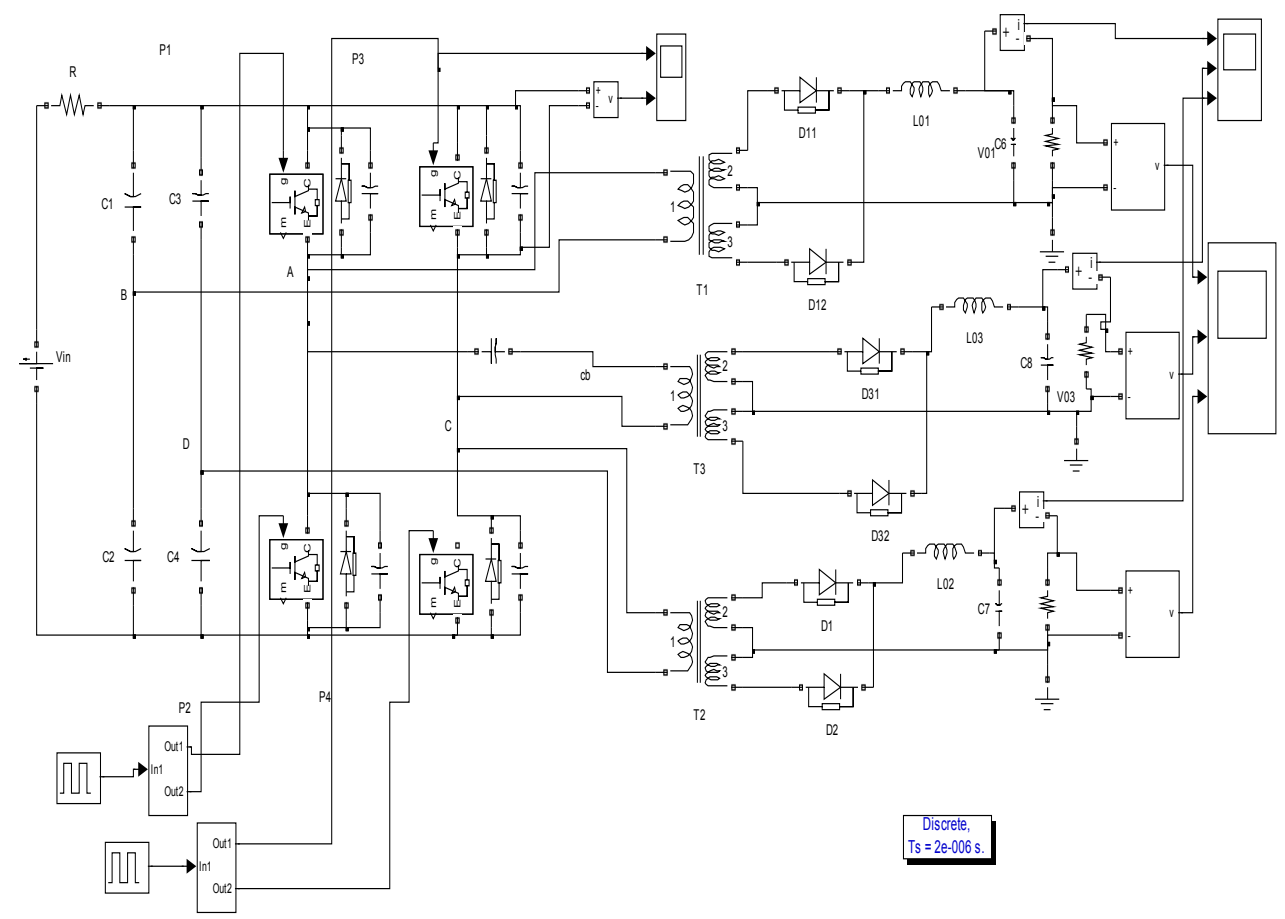

Figure 14: Simulink model of open loopmultiple outputs DC-DC converter.


Figure 15: Control signal of the multiple outputs converter.

into alternative current. The output of the inverter is fed to the linear transformer, and connected to diode bridge rectifier which is converted alternative current into direct current [8].

The first output is regulated through the duty cycle control of the asymmetrical half bridge converter which is composed of switches
S1-S2 and capacitors C1-C2. The second output voltage outputs ${ }_{02}$ is regulated through the duty cycle control of the asymmetrical half bridge converter which is composed of switches S3-S4 and capacitors C3-C4. The third output voltage outputs ${ }_{03}$ is regulated through the phase shift of two asymmetrical half bridge converters. The control signal of the proposed three output converter as shown in the Figure 15. 
Citation: Prasad JS, Obulesh YP, Babu CS (2015) Closed Loop Control of Zero Voltage Switching DC-DC Converter to Generate Three Outputs. J Electr Electron Syst 4: 156. doi:10.4172/2332-0796.1000156

Page 6 of 12

\section{Zvs conditions of the three outputs Dc-Dc converter}

The Figures 16 and 17 shows the pulse and across the switch voltage. Two stages of ZVS conditions of switch as shown, when pulse is ON the voltage across the switch is zero and when pulse is OFF the voltage across the switch is zero. Figure 18 (a) shows ON state at ZVS condition of the switch 1 pulse and switch across the capacitor voltage and (b) shows OFF state of ZVS condition of the switch 1 pulse and switch across the capacitor voltage [9].

The Figures 19 and 20 shows the pulse and across the switch voltage. Two stages of ZVS conditions of switch as shown, when pulse is ON the voltage across the switch is zero and when pulse is OFF the voltage across the switch is zero. Figure 21a shows ON state at ZVS condition of the switch 2 pulse and switch across the capacitor voltage and (b) shows OFF state at ZVS condition of the switch 2 pulses and switch across the capacitor voltage.

\section{Closed Loop Control of the Three Multilpe Outputs Dc- Dc Converter}

In this closed loop mode we are also taken $400 \mathrm{~V}$ as an input voltage. The output voltage of the inverter is connected to the three single phase transformers and to diode bridge rectifier to convert alternative voltage onto direct voltage. Three different output voltages $48 \mathrm{~V} / 10 \mathrm{~A}, 12 \mathrm{~V} / 5 \mathrm{~A}$ and $5 \mathrm{~V} / 20 \mathrm{~A}$ are obtained. The block diagram of proposed closed loop control of ZVS DC -DC converter is shown in Figure 21. The Simulink model of the closed loop proposed three output voltage converter as shown in the Figure 22 [10].

The detailed control block of the closed loop proposed three output converters as shown in the Figure 22. In this model we are taken three outputs as a feedback control. Compare the reference voltage and feedback voltage by using error amplifier. The error signal is given to PWM comparator to compare the ramp signal which is having 1000 $\mathrm{Hz}$ frequency and error signals and gives pulse to the switch S4 and


Figure 16: Switch 1 pulse and switch across the capacitor voltage.
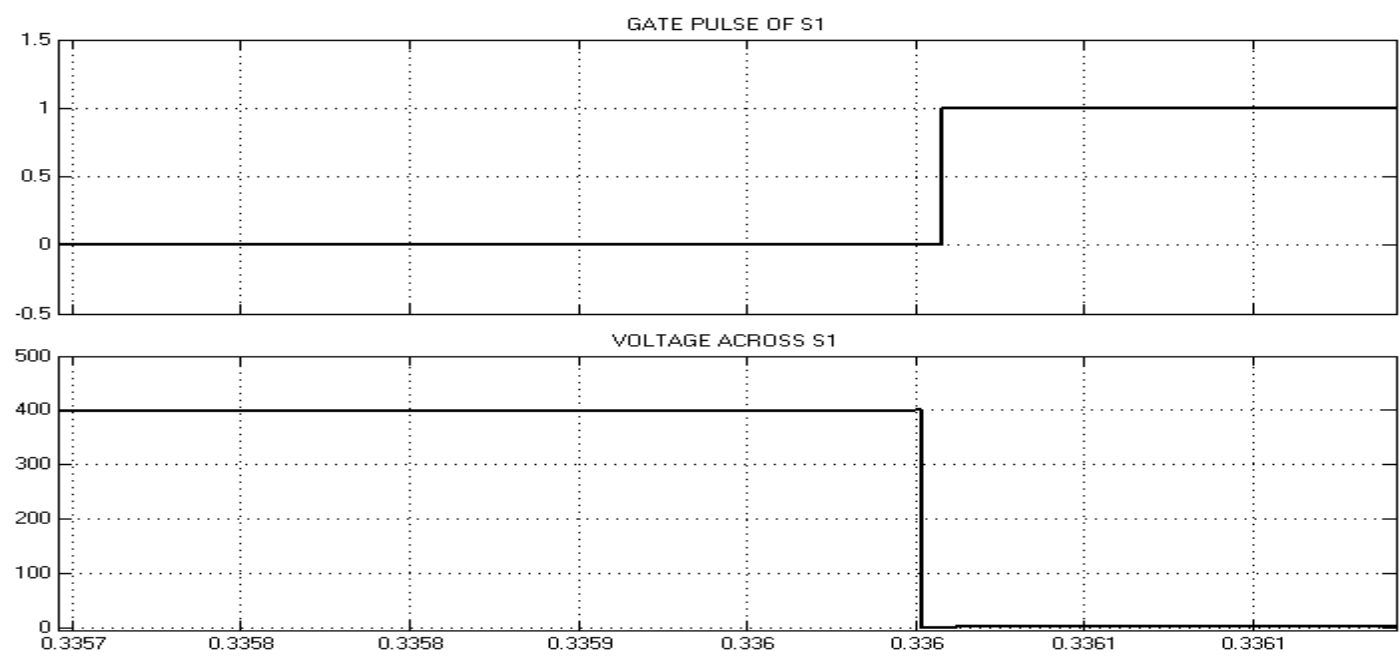

Figure 17a: ZVS condition of Switch 1 from Off-On state. 
Citation: Prasad JS, Obulesh YP, Babu CS (2015) Closed Loop Control of Zero Voltage Switching DC-DC Converter to Generate Three Outputs. J Electr Electron Syst 4: 156. doi:10.4172/2332-0796.1000156



Figure 17b: ZVS condition of Switch 1 from On-Off state.



Figure 18: Switch 2 pulse and switch across the capacitor voltage

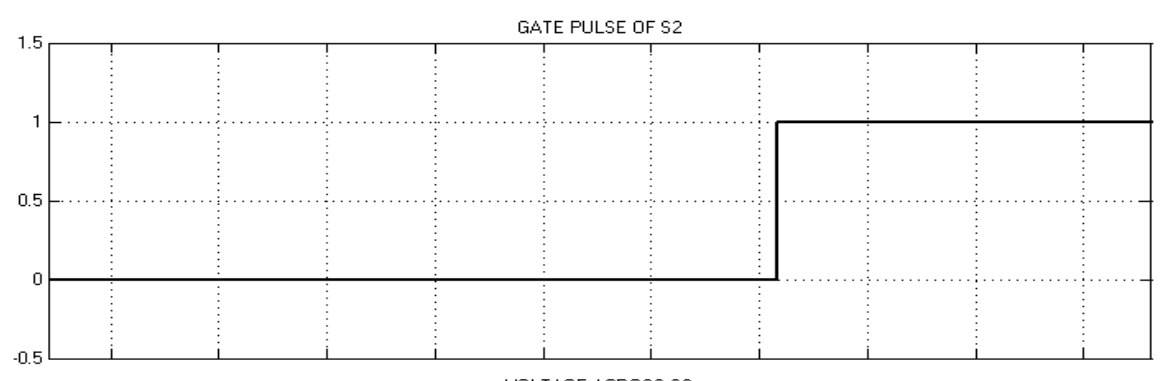

VOLTAGE ACROSS S2

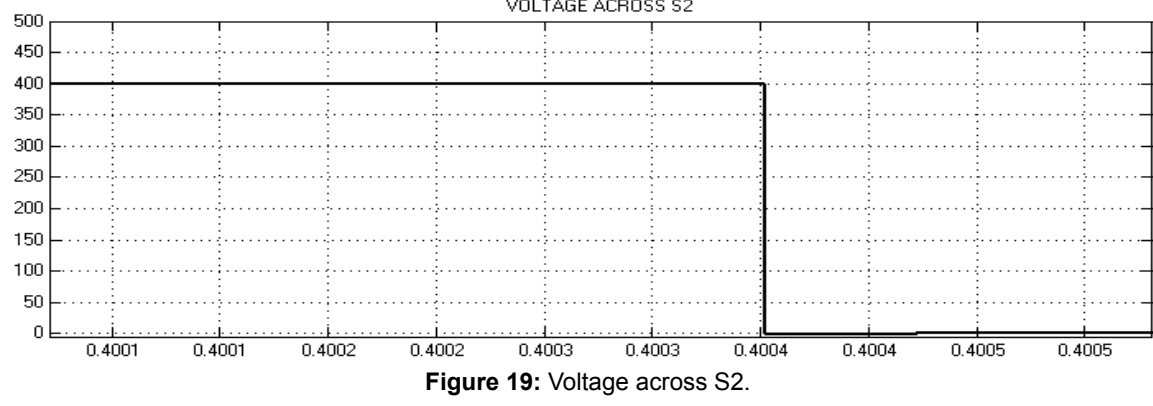


Citation: Prasad JS, Obulesh YP, Babu CS (2015) Closed Loop Control of Zero Voltage Switching DC-DC Converter to Generate Three Outputs. J Electr Electron Syst 4: 156. doi:10.4172/2332-0796.1000156
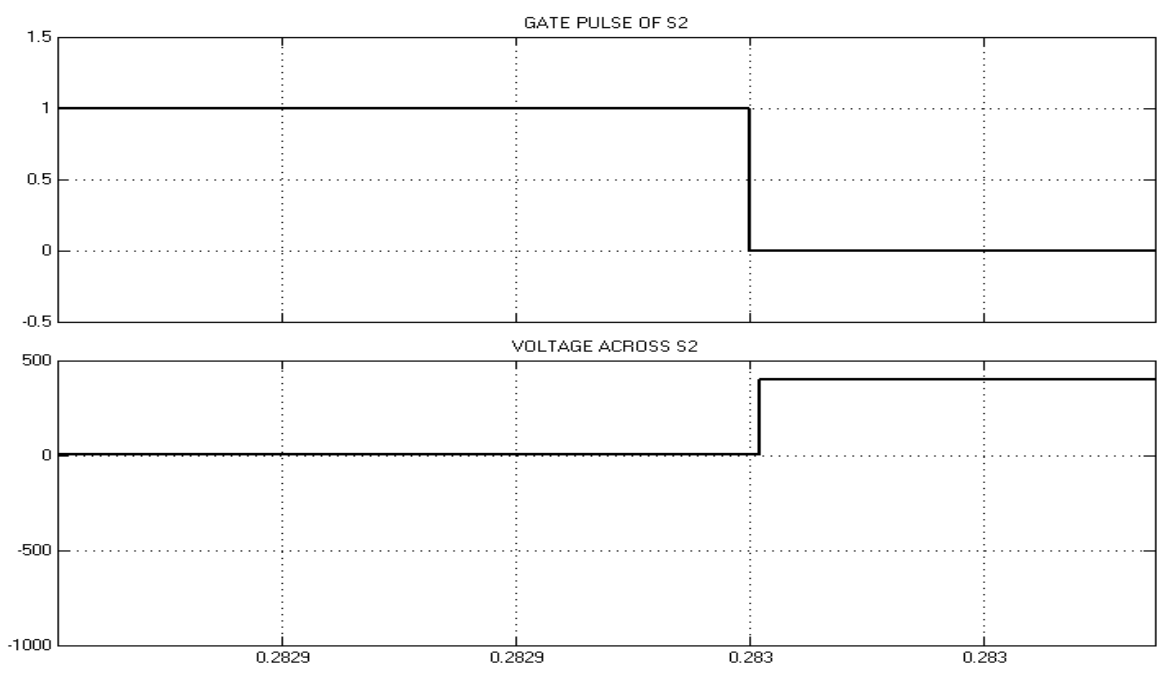

Figure 20: output voltage wave forms of the proposed three outputs converter
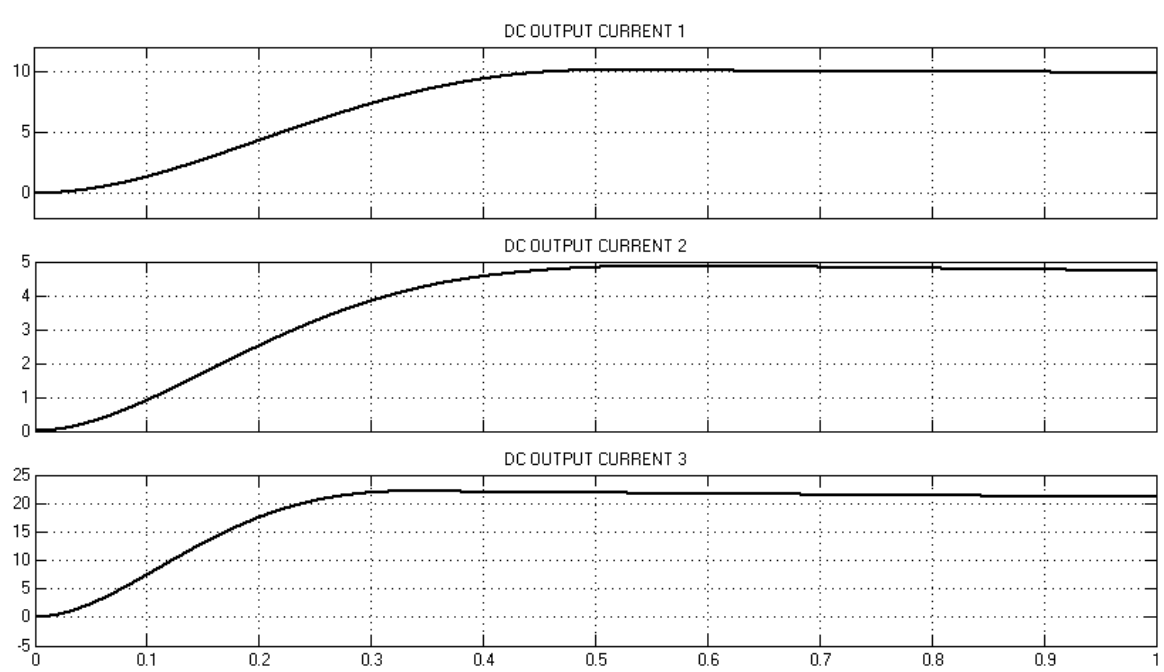

Figure 21: Output current wave forms of the proposed three outputs converter.

inverted pulse is given to the switch S3 of the proposed three outputs converter. By using remaining two outputs we generate a pulse and it is given to the switch $\mathrm{S} 1$ and inverted pulse is given to the switch $\mathrm{S} 2$ of the proposed three outputs converter [5].

During the time of turn-off and turn-on conditions, the power electronic devices have to withstand large currents and voltages, thus resulting in the high switching stresses and switching losses. To reduce the switching losses and stress we are using zero voltage switching (ZVS). Zero voltage switching (ZVS) conditions of the converter are pulse and switch across capacitor voltages as shown in figures. The zero voltage switching (ZVS) conditions of the four switches at ON time and OFF time period of the pulses and switch across the capacitor voltages are as shown in the below Figure 23.

\section{Zvs conditions of the three multiple outputs Dc-Dc converter under closed loop}

The Figures 24 and 25 shows the pulse and across the switch voltage of S1. Two stages of ZVS conditions of switch S1 as shown, when pulse is $\mathrm{ON}$ the voltage across the switch is zero and when pulse is OFF the voltage across the switch is zero.

The Figures 26 and 27 shows the pulse and across the switch voltage of S1. Two stages of ZVS conditions of switch S1 as shown, when pulse is $\mathrm{ON}$ the voltage across the switch is zero and when pulse is off the voltage across the switch is zero [4].

By using the closed loop control signal we can regulate the three outputs with changing load value. The output voltage and current wave forms of closed loop control of the proposed three outputs converter as shown in the Figure 28 [7].

\section{Conclusions}

Outputs were regulated through primary side switches when proportional sharing was directly used in Multiple-output ZVS dcdc converter. All the main switches can realize ZVS, therefore the converter can work with higher switching frequency and higher 




Figure 22: Proposed closed loop control circuit of ZVS DC-DC converter.

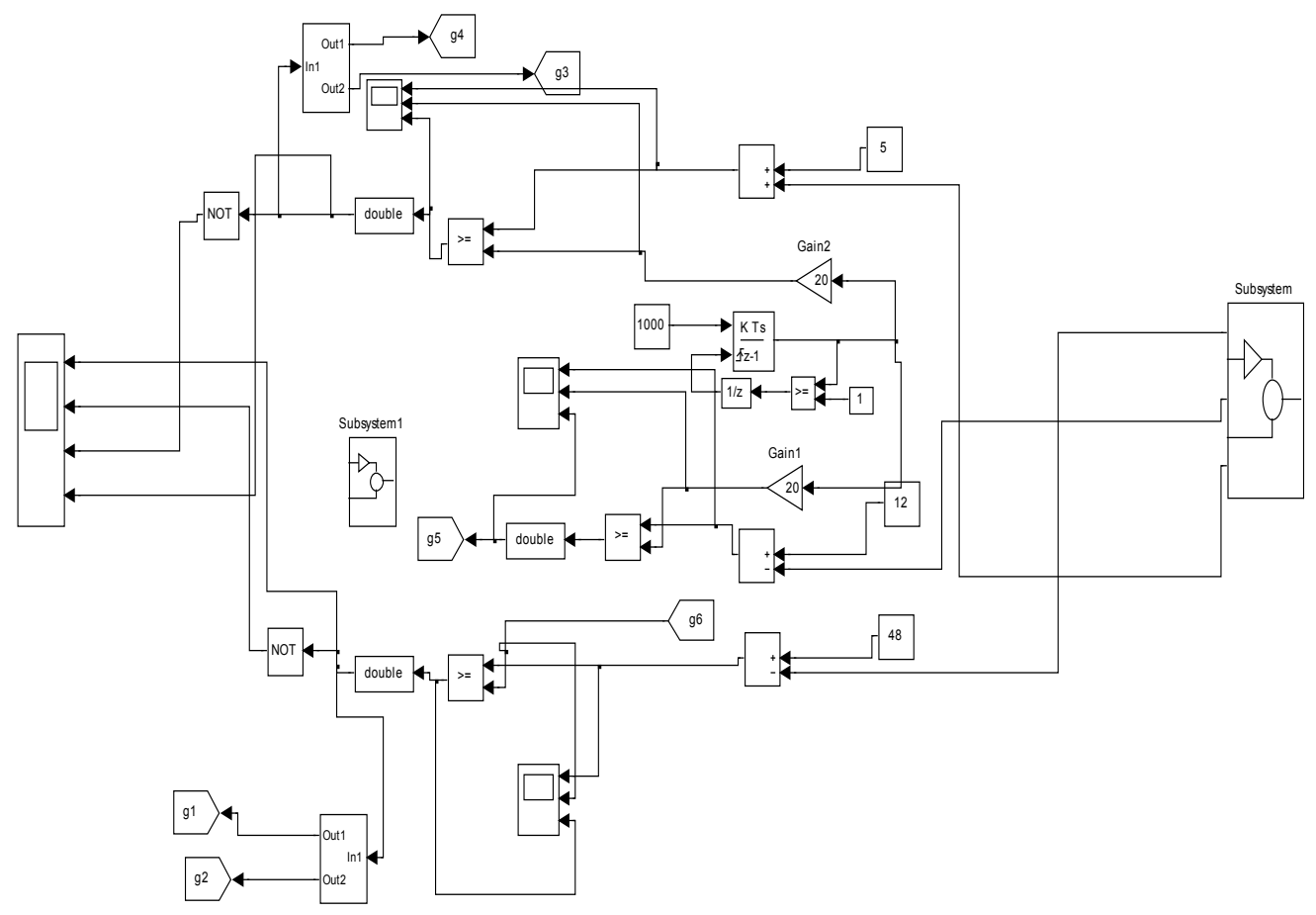

Figure 23: Simulink model of closed loop control of proposed three multiple outputs dc-dc converter. 
Citation: Prasad JS, Obulesh YP, Babu CS (2015) Closed Loop Control of Zero Voltage Switching DC-DC Converter to Generate Three Outputs. J Electr Electron Syst 4: 156. doi:10.4172/2332-0796.1000156
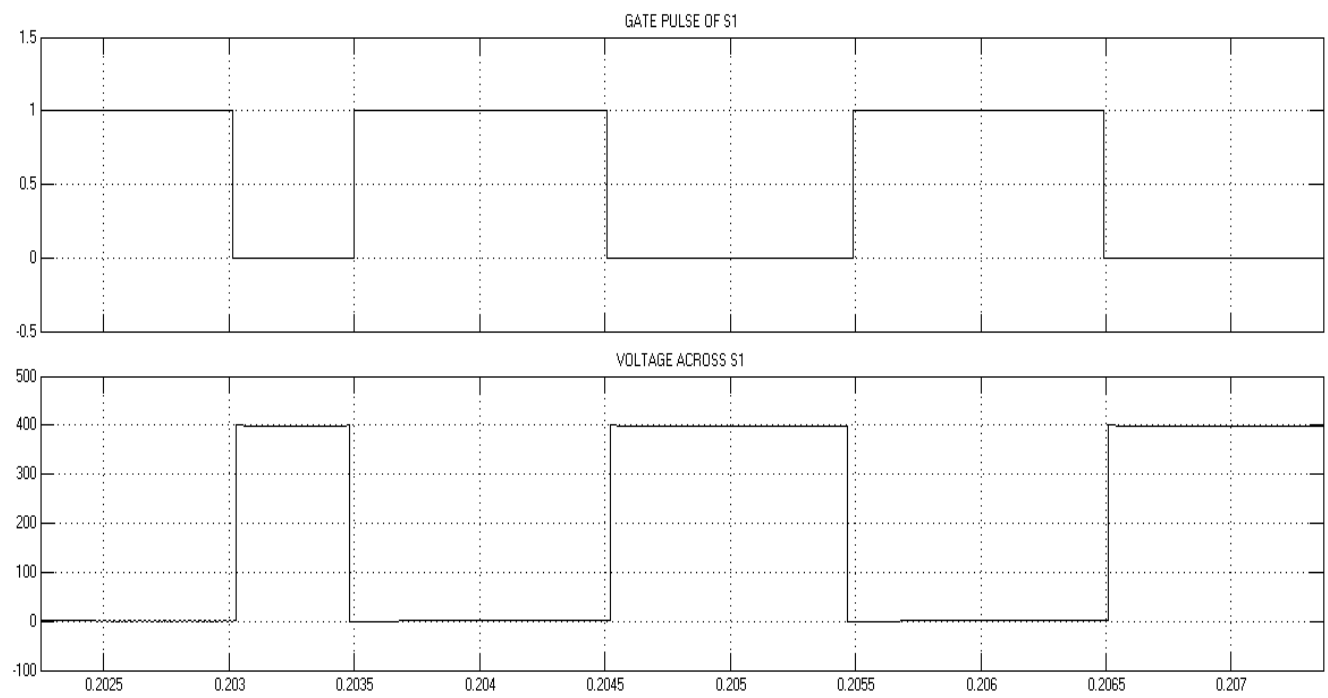

Figure 24: Switch 1 pulse and switch across the capacitor voltage.
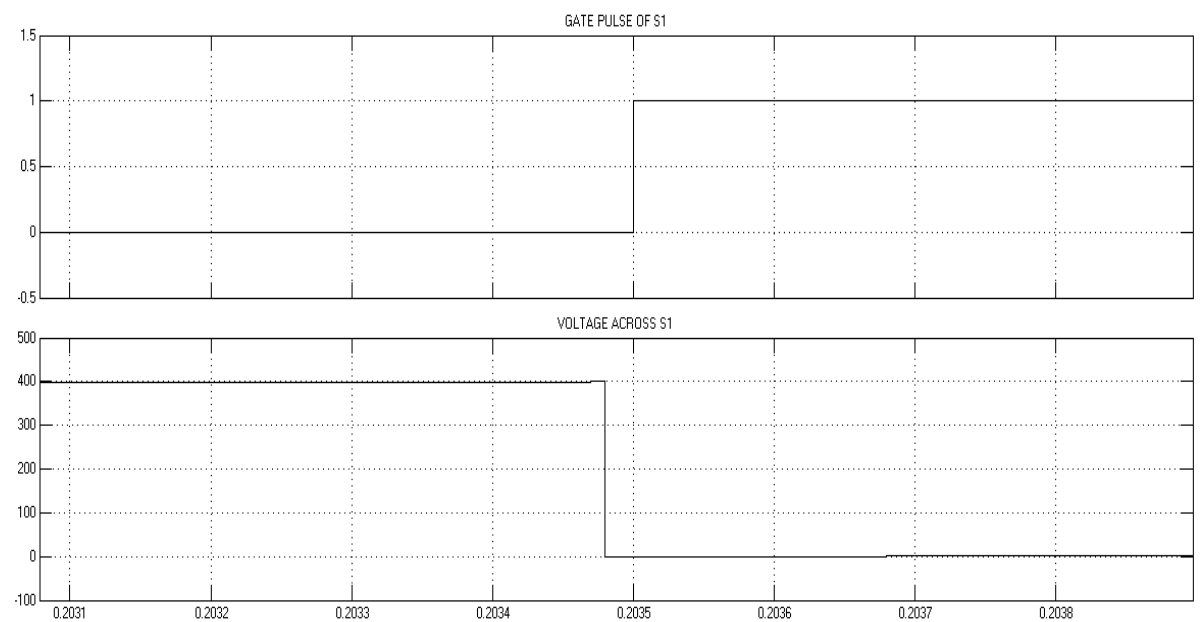

(a)
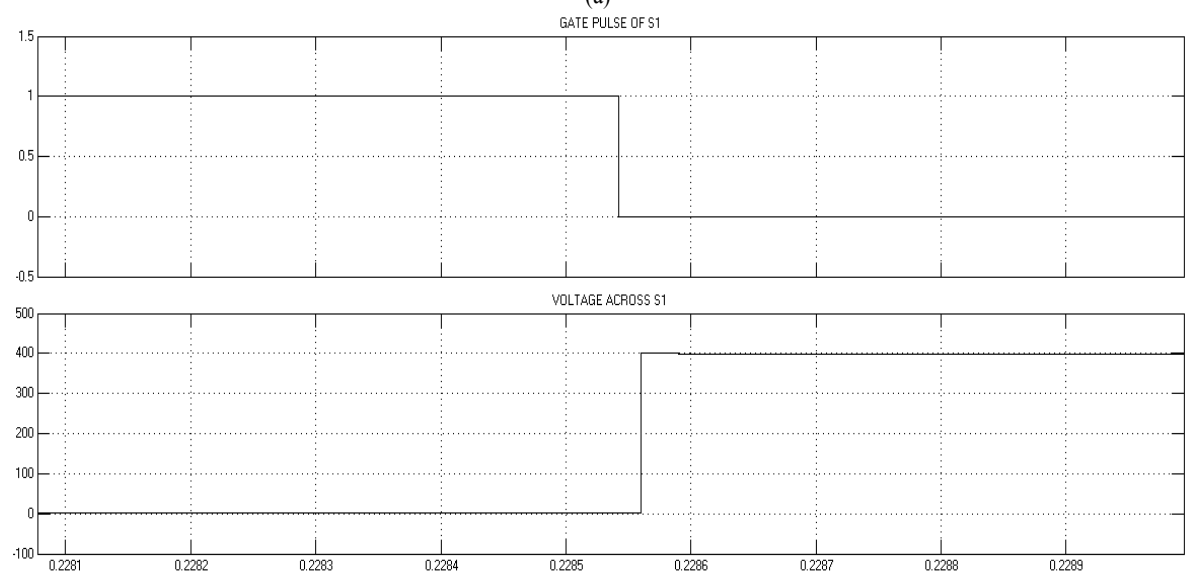

(b)

Figure 25: (a) shows ON state at ZVS condition of the switch 1 pulse and switch across the capacitor voltage and (b) shows OFF state at ZVS condition of the switch 1 pulse and switch across the capacitor voltage. 
Citation: Prasad JS, Obulesh YP, Babu CS (2015) Closed Loop Control of Zero Voltage Switching DC-DC Converter to Generate Three Outputs. J Electr Electron Syst 4: 156. doi:10.4172/2332-0796.1000156
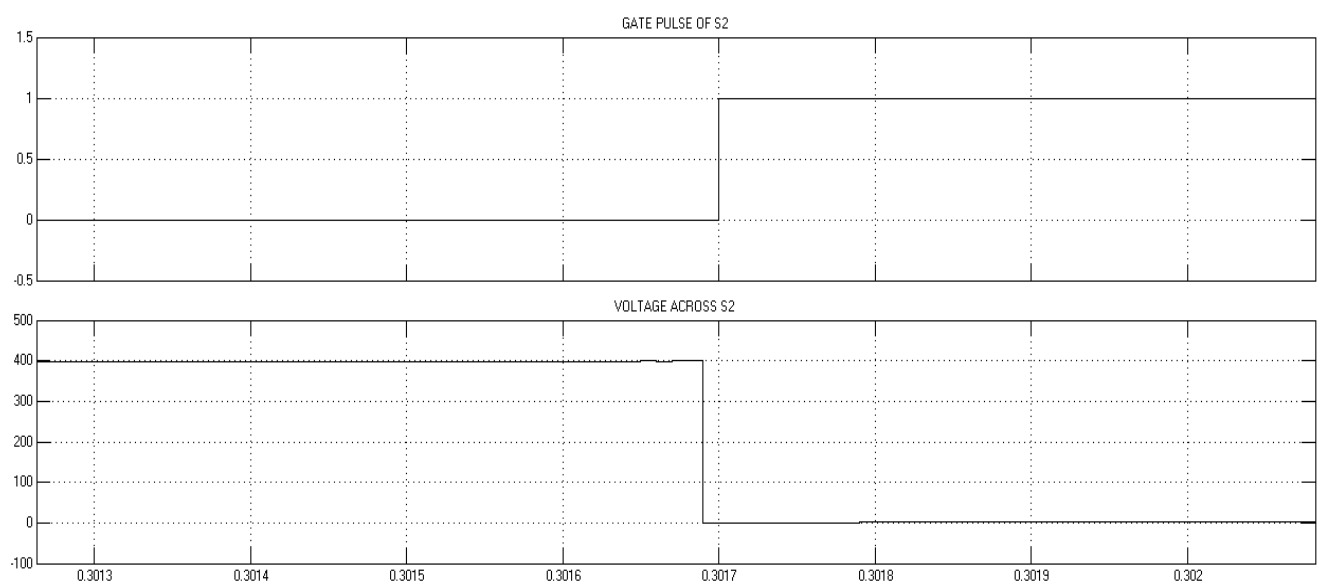

(a)
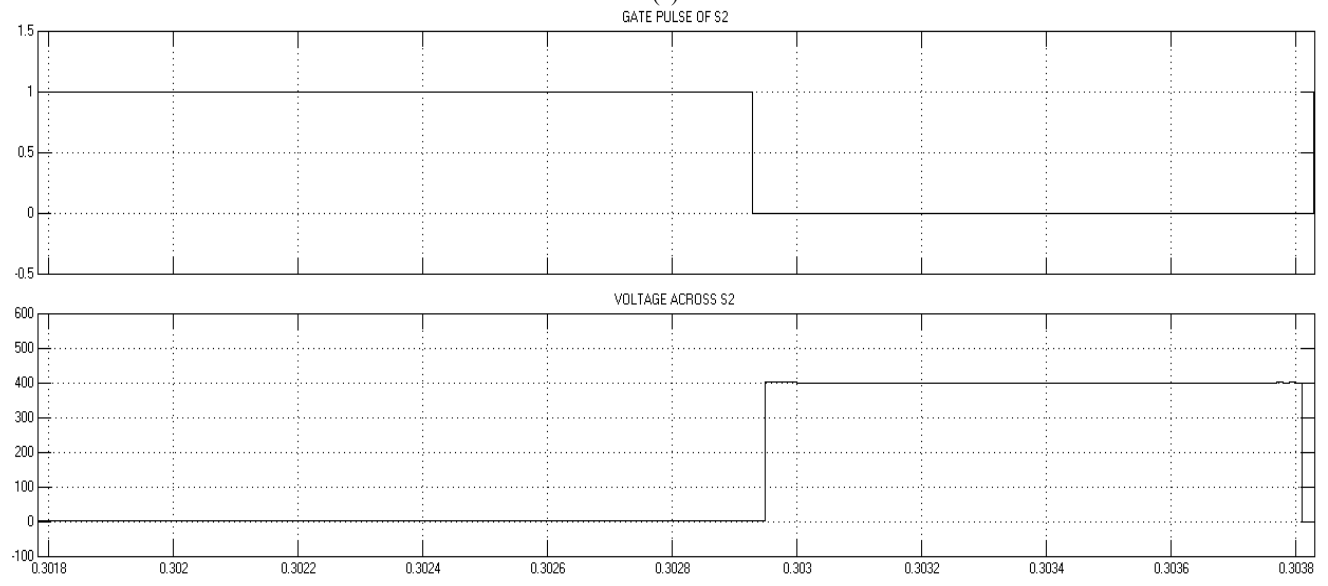

(b)

Figure 26: (a) shows ON state at ZVS condition of the switch 2 pulse and switch across the capacitor voltage and (b) shows OFF state at ZVS condition of the switch 1 pulse and switch across the capacitor voltage.
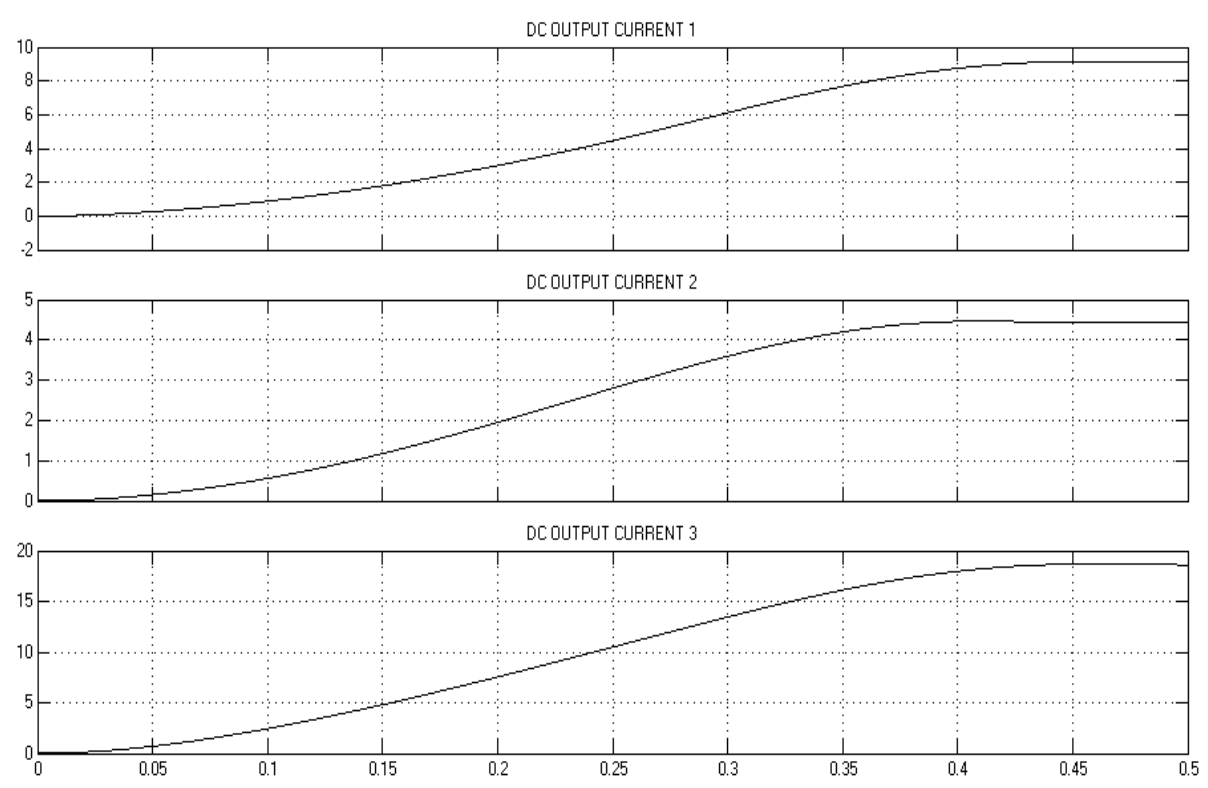

Figure 27: Output current waveforms of closed loop control of the proposed three output converter. 
Citation: Prasad JS, Obulesh YP, Babu CS (2015) Closed Loop Control of Zero Voltage Switching DC-DC Converter to Generate Three Outputs. J Electr Electron Syst 4: 156. doi:10.4172/2332-0796.1000156

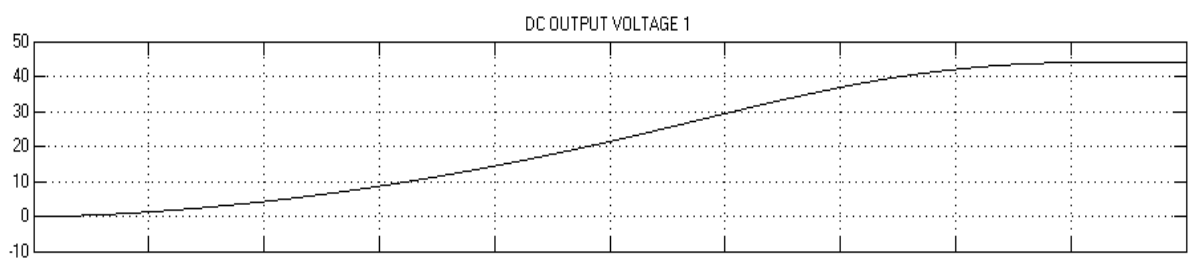

DC OUTPUT VOLTAGE 2
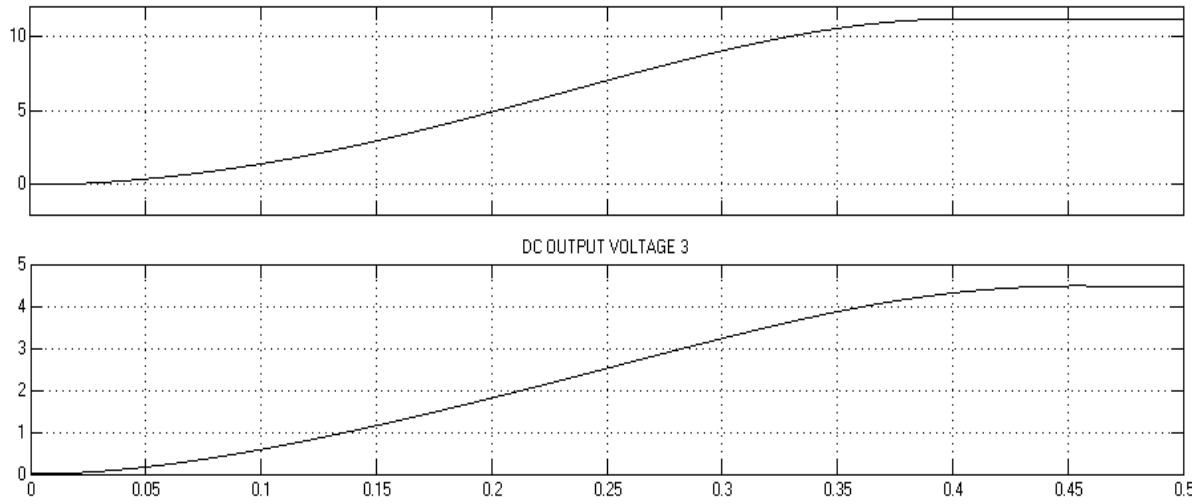

Figure 28: Output voltage waveforms of closed loop control of the proposed three output converter.

efficiency. The operation stages, ZVS condition and control details are also analyzed. Although in the proposed converter there are two and three bridge legs and three and five outputs, it can be extended to number of bridge legs and 2-1 outputs. In the proposed multipleoutput ZVS dc-dc converter, there are two and three bridge legs and three and five outputs. However, the number of the bridge legs is not limited. We can add another bridge leg, two transformers and two rectification circuits to produce additional two outputs. A generalized principle is that it can produce 2-1 outputs where the number of bridge legs is. The simulation of three multiple and five multiple output zerovoltage switching DC-DC converter was implemented [3].

\section{References}

1. Lin CBR, Chia-Hung C (2013) Analysis of Interleaved Three level ZVS converter with series connected transformers, IEEE Trans on Power Electronics 28: 3088-3099.

2. Mousavi A, Das $P$, Moschopoulos G (2012) A Comparative study of a new ZCS dc-dc full bridge boost converter with a ZVS active clamp converter, IEEE Trans. on Power Electronics 27: 1347-1357.

3. Alexander JC, Rowden B, Balda JC (2009) A Three level Full bridge Zero voltage Zero current switching converter with a simplified switching scheme, IEEE Trans. on Power Electronics 24: 329-3381.
4. dos Giacomini PGS, Scholtz JS, Mezaroba M (2008) Step-Up/Step-Down DC-DC ZVS PWM Converter With Active Clamping, IEEE Trans on Industrial Electronics 55: 3635-3643.

5. Lin BR, Huang CL, Wan JF (2008) Analysis, Design, and Implementation of a Parallel ZVS Converter, IEEE Trans on Industrial Electronics 55: 1586-1594.

6. Xinke Wu, Junming Zhang, Xin Ye, Qian Z (2008) Analysis and Derivations for a Family ZVS Converter Based on a New Active Clamp ZVS Cell, IEEE Trans on Industrial Electronics 55: 773-781.

7. Wang CM, Su CH, Jiang MC, Lin YC (2008) A ZVS-PWM Single-Phase Inverter Using a Simple ZVS-PWM Commutation Cell, IEEE Trans on Industrial Electronics 55: 758-766.

8. Chen W, Ruan X (2008) Zero-Voltage-Switching PWM Hybrid Full-Bridge Three-Level Converter With Secondary-Voltage Clamping Scheme, IEEE Trans. on Industrial Electronics 55: 644-654.

9. Wu TF, Lai YS, Hung JC, Chen YM (2008) Boost Converter with Coupled Inductors and Buck- Boost Type of Active Clamp, IEEE Trans on Industrial Electronics 55: 154-162.

10. Lee SS, Choi SW, Moon GW (2007) High-Efficiency Active-Clamp Forward Converter with Transient Current Build-Up (TCB) ZVS Technique, IEEE Trans on Industrial Electronics 54: 310-318. 